\title{
Serum matrix metalloproteinase-9 levels and severity of symptoms in boys with attention deficit hyperactivity disorder ADHD/ hyperkinetic disorder HKD
}

\author{
Halina Kadziela-Olech • Piotr Cichocki • \\ Justyna Chwiesko $\cdot$ Jerzy Konstantynowicz • \\ Jan Józef Braszko
}

Received: 18 July 2013 / Accepted: 26 February 2014/Published online: 17 March 2014

(C) The Author(s) 2014. This article is published with open access at Springerlink.com

\begin{abstract}
The serum levels of matrix metalloproteinase-9 (MMP-9) in neuropsychiatric disorders of adults have been widely investigated. So far, no studies have been conducted on the relationship of MMP-9 and cognitive domains in children with two phenotype models, attention deficit/ hyperactivity disorder and hyperkinetic disorder (ADHD/ HKD). The aim of this research was to evaluate and test the hypothesis that serum MMP-9 levels are associated with the severity of symptoms in children with ADHD/HKD and to compare the results in two models of this disorder. The study group comprised 37 Caucasian boys aged 7-12 years with HKD, being a subset of the combined ADHD subtype. Intellectual functions were measured using Wechsler Intelligence Scale for Children-Revised. The analysis of serum concentrations of MMP-9 was based on a quantitative sandwich ELISA. The statistical regression analysis revealed a correlation between increased serum MMP-9 levels and severity of symptoms in the ADHD $(\beta=0.33$; $p=0.043)$ and HKD $(\beta=0.34, p=0.037)$ model. According to the results, elevated levels of serum MMP-9 in boys with HKD may be associated with clinical impulsivity domain $(\beta=0.38 ; p=0.019)$.
\end{abstract}

Keywords ADHD $\cdot$ HKD $\cdot$ Cognitive $\cdot$ Behaviours · MMP-9 - Boys

H. Kadziela-Olech $(\bowtie) \cdot$ P. Cichocki · J. Chwiesko .

J. Konstantynowicz · J. J. Braszko

Medical University, Bialystok, Podlaskie, Poland

e-mail: halina.kadziela-olech@umb.edu.pl

\section{Introduction}

Matrix metalloproteinases (MMPs) (zinc-dependent proteinases) play important roles in extracellular matrix (ECM) remodelling in physiological and pathological processes [1-6]. The ECM is not only a mechanical support for its constituent cells, but also participates in the regulation of metabolism and in the exchange of information with the environment. To accomplish these functions, the matrix should undergo constant transformation. The imbalance between decay and renewal of ECM is characteristic of most pathologies as their primary or secondary cause [7, 8]. Matrix metalloproteinases are not only able to cleave all the constituents of ECM proteins, but also to activate or deactivate other numerous "signalling" molecules, such as receptors, adhesion molecules and growth factors $[1,5,9,10]$.

Matrix metalloproteinase-9 (MMP-9), a typical ECM protease (gelatinase), is characterized by a wide range of substrates in vitro $[4,6]$. Recently, a convincing support for the involvement of MMP-9 in inflammation, autoimmune diseases, cancer metastases and physical injuries has been reported [5]. Recent studies have also focused on the relationship of MMP-9 with the neurological disorders in adults, and its possible role in the reorganisation of ECM after injuries of the nervous system. This gelatinase plays an important role in system dysfunction of the blood-brain barrier [11-15], and its level can be assessed in the plasma [17-19]. The serum levels of MMP-9 in neuropsychiatric disorders in adults have been widely studied. The data focus an potential association of MMP-9 with depression, schizophrenia and bipolar disorder in adults [20]. The results of experiments using rodent models showed a role of MMP-9 in epileptogenesis [21]. Many studies indicate that cognitive dysfunctions may be associated with changes 
in MMP-9 activity [11, 17, 22-24], and show the importance of MMP-9 in cognitive dysfunctions of adult patients with dementia [19, 25], cerebral ischemia [11, 13, 14, 17] or neuropsychiatric symptoms in autoimmune diseases [16]. So far, no studies have been conducted on the relationship of MMP-9 and cognitive function in children with attention deficit/hyperactivity disorder and hyperkinetic disorder (ADHD/HKD).

Cognitive deficits and behavioural symptoms in ADHD have been studied intensely and are well documented [2634]. They are classified according to DSM-IVR [35] and DSM-V [36], or ICD-10 [37]. These procedural approaches to both classifications show some differences. The cognitive symptoms of ADHD cover two domains: inattention and hyperactivity/impulsivity. In the version of DSM-IVR or DSM-V, three subtypes have been proposed and evaluated: ADHD predominately inattentive, predominately hyperactive/impulsive (if symptoms involve only one domain) or combined. According to ICD-10, HKD can be diagnosed when symptoms belonging to all the domains are observed, including inattention, hyperactivity and impulsivity.

Neuropsychological studies concerning ADHD show a variety of cognitive deficits, altered level of motivational processes and irregularities in the stages of processing and storage of information in the brain [30-33, 38-40]. Intellectual and neuropsychological abilities in ADHD have been investigated for many years [41-43]. Children with ADHD exhibit a wide range of performance deficits across a range of neuropsychological domains, including response inhibition, working memory, planning, sense of time, sustained attention, and Verbal learning [28, 31-33, 43-45]. Many studies have attempted to determine the characteristic profiles of the intellectual capacity of children with ADHD [27, 42, 46, 47]. Children with ADHD have a lower overall level of intellectual ability than their healthy peers [27, 32, 43, 47], but a similar decrease is also observed in children with other neuropsychiatric disorders [42, 46]. Several studies also point to a difference between Verbal and performance IQ in children with ADHD as compared with healthy children [27, 40, 46, 47], whereas others provide contradictory results regarding these cognitive aspects [40, 42, 48]. Research to date could not fully explain neuropsychiatric deficits in the functioning of children with ADHD and their response to treatment. Differences in the research paradigms along with the heterogeneity of the disease phenotypes are, at least partly, responsible for the problem.

Despite of intense research in recent decades, the brain processes and mechanisms which underlie the cognitive deficits of ADHD are unclear. It can be assumed, that the reorganization of the brain responsible for behavioural and cognitive symptoms of $\mathrm{ADHD} / \mathrm{HKD}$, and changes in the activity of MMP-9 may be the result of ECM reconfiguration in this disorder. To date, serum MMP-9 levels in children with ADHD/HKD have not been studied. Therefore, the aim of this study was to evaluate associations between serum MMP-9 levels and the symptoms severity in children with ADHD/HKD. We hypothesized that the activity of MMP-9 may be related to intensity of symptoms and the degree of cognitive dysfunction in children with ADHD/HKD.

\section{Methods}

Participants and procedure

The study group comprised 37 Caucasian boys with Combined ADHD subtype and HKD, aged between 7 and 12 years (median 9.2 years; 25 th percentile -7 and 75 th percentile 11 years). The study group was selected among patients with hyperactivity symptoms from primary care, who had been referred to the specialized psychiatric diagnosis and therapy at the Child and Adolescent Psychiatry Unit of the University Children's Hospital in Bialystok (Poland).

The presence of several inattentive or hyperactive, impulsive symptoms in two or more situation (at home, school, in other activities) is required for the diagnosis of ADHD/HKD [35-37]. Attention deficit/hyperactivity disorder symptoms at study baseline were measured using the NICHQ Vanderbilt Assessment Scale for Parent (VADPRS) and for Teacher (VADTRS) [49], each of which being divided into two sections: symptoms and performance. The VADPRS contains 47 items, and VADTRS includes 35 items of symptoms and 8 items of performance. The construction of the toolkit is based on the Diagnostic and Statistical Manual of Mental Disorders, Fourth Edition (DSM-IV) [35], and includes the 18 ADHD items (9inattention and 9-hyperactive/impulsive symptoms), and as well as a screen for the following coexisting conditions: oppositional-defiant disorder, conduct disorder, anxiety and depression. The 4-point Likert scale rates the severity of symptoms (i.e., $0=$ never, $1=$ occasionally, $2=$ often, and $3=$ very often), whereas the 5-point Likert scale assesses performance (i.e., $1=$ excellent, $2=$ above average, $3=$ average, $4=$ somewhat of a problem, $5=$ problematic). For Combined Inattention/Hyperactivity subtype, at least six of nine items of inattention and at least six of nine items of hyperactive/impulsivity need to score two or three points, with at least one of performance questions scoring four or five points. The internal consistency and structure of the Vanderbilt Assessment Scales are acceptable and consistent with DSM-IV and other accepted measures of ADHD [50, 51]. This toolkit has 
recommendations of American Academy of Pediatrics as a framework for diagnostic decision making in a child 6-12 years old [49].

Both classifications were used to identify a homogeneous phenotype of HKD/ADHD. The diagnosis of Combined ADHD subtype was ascertained using current DSMIV criteria [35], stating that one must have at least six positive responses to either the inattentive nine and six out of nine items on hyperactive/impulsive nine core symptoms. The diagnosis of HKD was performed according to the criteria of ICD-10 [37], requiring symptoms of three domains (at least six of nine items of inattention, at least three of five items of hyperactive and at least one of four of impulsivity). In the study group, these symptoms were present before the child reached 7 years of age, in a number of situations, continued on regular basis for more than 6 months and significantly impaired the child's academic and social functioning. For the study, the 18 ADHD items were examined by separating symptoms into subscales of inattention, hyperactivity and impulsivity. Mean (SD) subscale scores were computed across each rate for each symptom domain.

Each examination comprised observation of the family and other informants, attention being paid to parents/ guardians personality traits and attitudes to the child, relationships of parents, the child's behaviour towards his/ her parents/guardians, the child's behaviour and spontaneous play and group functioning. Exclusion criteria of the study were the coexistence of other psychiatric or neurodevelopmental disorders (e.g. autistic spectrum, obsessivecompulsive, oppositional-defiant, conduct disorders, anxiety, depression, tics), epilepsy, mental retardation and somatic diseases. None of these boys had history of pharmacological treatment.

All participants in the study were administered the Wechsler Intelligence Scale for Children-Revised (WISC$\mathrm{R}$, Polish adaptation) [52]. The intelligence quotient was evaluated by a certified psychologist. Wechsler Intelligence Scale for Children-Revised includes Verbal (subtests: general information, similarities, arithmetic, Vocabulary, understanding) and performance (subtests: picture completion, picture arrangement, block design, object assembly, coding-digit symbol) scales. Raw scores obtained in subtests results were restated for conversion in accordance with the standards of the corresponding age group. The sum of the results converted from individual subtests create an overall score for the Verbal and performance scales. The values corresponded to the amount of IQ results translated into Verbal scales, wordless, and full of different age groups. In addition to the standard deviation scores of these subtests, Verbal intelligence scale, performance scale, and full-scale IQ coefficients were calculated. The mean value for all intelligence scales was 100 and the standard deviation 15 . The diagnosis of children was confirmed by certified psychiatrist and psychologist.

Venous blood samples of each child with ADHD were taken during the run psychiatric and psychological diagnosis. After centrifugation, the serum was frozen and stored at $-70{ }^{\circ} \mathrm{C}$ until the time of the signs. Matrix metalloproteinase- 9 activity in the serum was determined by ELISA, using a kit Human ELISA System Biotrak (GE Healthcare, Amersham Biosciences) and expressed in $\mu \mathrm{g} / \mathrm{l}$. To minimize assay variance, serum levels of MMP-9 from each subject were measured on the same day. The assay was based on a two-site ELISA sandwich format using two antibodies directed against different epitopes of MMP-9. Protocols were performed according to the manufacturer's instructions. The sensitivity defined as two standard deviations above the zero dose binding was determined as $0.6 \mu \mathrm{g} / \mathrm{l}$, assay range $4-128 \mu \mathrm{g} / \mathrm{l}$.

\section{Statistical analysis}

All statistical analyses were performed using the Statistica 10.0 PL (StatSoft). Since many variables were not normally distributed according to the Shapiro-Wilk test, the analysis used non-parametric tests: the Kruskal-Wallis test with post hoc test, Mann-Whitney $U$ test and Spearman's rank correlation. The values of the variables are presented as mean $\pm \mathrm{SD}$ or median, first and third quartile. The regression analysis was performed. The univariate linear regression models were created. The $p$ value $<0.05$ was considered statistically significant.

The study was approved by the Ethical Committee of the Medical University of Bialystok, in accordance with the principles of Guidelines for Good Clinical Practice R-I/ 003/168.

\section{Results}

Both models (HKD and combined ADHD subtype) were identified in every boy in the study group. Total scores were similar for the clinical model of HKD (mean \pm SD: $14.68 \pm 2.00$; median 14, first and third quartile:14-16) and ADHD (mean \pm SD: $14.76 \pm 1.62$; median 14, first and third quartile:14-16). No significant differences were noted between the average values of VADPRS (mean \pm SD: $39.95 \pm 6.81$ ) and VADTRS (mean \pm SD: $38.14 \pm 6.14$ ) in the study group. There were significant positive correlations between ICD-10 and DSM-IV symptoms $\left(R_{\mathrm{s}}=0.95 ; p<0.001\right)$ and VADPRS $\left(R_{\mathrm{s}}=0.69\right.$; $p=0.001$ ) (Table 1). In addition, the interrelationship between HKD and ADHD domains was tested. The number of hyperactivity symptoms of HKD correlated significantly with hyperactivity/impulsivity of ADHD $\left(R_{\mathrm{s}}=0.76\right.$; 
Table 1 Cognitive domains and intellectual functions in boys with HKD
The comparison of DSM-IV to ICD-10. Statistical coherence of values was determined by Spearman's rank correlation test. The statistical correlation between intellectual functions and domains of HKD was determined by Spearman's rank correlation test

$R_{\mathrm{S}}$ Spearman's rank correlation coefficient

* Significant correlation at the 0.05 level (two-sided)

** Significant correlation at the 0.01 level (two-sided)

\begin{tabular}{|c|c|c|c|c|c|c|c|}
\hline & \multirow[t]{3}{*}{ Mean (SD) } & \multicolumn{6}{|c|}{ HKD model } \\
\hline & & \multicolumn{2}{|c|}{ Inattention } & \multicolumn{2}{|c|}{ Hyperactivity } & \multicolumn{2}{|c|}{ Impulsivity } \\
\hline & & $R_{\mathrm{s}}$ & $p^{*}, * *$ & $R_{\mathrm{s}}$ & $p^{*, * *}$ & $R_{\mathrm{s}}$ & $p^{*, * *}$ \\
\hline ICD (total) & $14.68(2.00)$ & $0.82 * *$ & $<0.001$ & $0.70^{* *}$ & $<0.001$ & $0.38 *$ & 0.019 \\
\hline Inattention & $7.11(1.17)$ & 1 & & 0.32 & & 0.24 & \\
\hline Impulsivity & $3.16(0.73)$ & 0.24 & & -0.10 & & 1 & \\
\hline Hyperactivity & $4.43(1.12)$ & 0.32 & & 1 & & -0.10 & \\
\hline \multicolumn{8}{|l|}{ Combined ADHD subtype } \\
\hline DSM-IV (total) & $14.76(1.62)$ & $0.89 * *$ & $<0.001$ & $0.56^{* *}$ & $<0.001$ & $0.35^{*}$ & 0.03 \\
\hline Inattention & $7.03(1.14)$ & $0.92 * *$ & $<0.001$ & 0.26 & & 0.27 & \\
\hline Hyperactivity/impulsivity & $7.73(0.87)$ & & & $0.76^{* *}$ & $<0.001$ & 0.32 & \\
\hline VADPRS (total) & $39.95(6.81)$ & $0.73 * *$ & $<0.001$ & $0.35^{*}$ & 0.03 & 0.26 & \\
\hline Inattention & $19.29(4.31)$ & $0.74 * *$ & $<0.001$ & 0.08 & & 0.25 & \\
\hline Hyperactivity/impulsivity & $20.68(3.57)$ & $0.50 * *$ & 0.001 & $0.61 * *$ & $<0.001$ & 0.20 & \\
\hline VADTRS (total) & $38.14(6.14)$ & 0.19 & & 0.05 & & 0.08 & \\
\hline Inattention & $19.27(3.68)$ & 0.23 & & 0.04 & & 0.09 & \\
\hline Hyperactivity/impulsivity & $19.03(3.81)$ & 0.22 & & 0.06 & & 0.10 & \\
\hline Total IQ & $98.43(14.12)$ & -0.21 & & 0.10 & & -0.10 & \\
\hline Verbal IQ & $99.40(15.31)$ & -0.11 & & 0.13 & & 0.02 & \\
\hline Performance IQ & $97.32(14.41)$ & -0.06 & & -0.01 & & -0.30 & \\
\hline Information & $10.38(3.34)$ & -0.09 & & 0.12 & & 0.15 & \\
\hline Similarities & $10.32(2.68)$ & -0.01 & & 0.15 & & 0.06 & \\
\hline Arithmetic & $8.95(3.47)$ & -0.06 & & -0.04 & & 0.07 & \\
\hline Vocabulary & $10.00(3.59)$ & $-0.42 * *$ & 0.01 & 0.21 & & -0.15 & \\
\hline Comprehension & $10.14(2.18)$ & $-0.49 * *$ & 0.002 & -0.05 & & -0.22 & \\
\hline Picture completion & $10.49(1.74)$ & -0.05 & & -0.10 & & 0.08 & \\
\hline Picture arrangement & $10.57(2.90)$ & -0.03 & & 0.19 & & -0.05 & \\
\hline Block design & $9.27(3.39)$ & 0.02 & & -0.04 & & -0.28 & \\
\hline Object assembly & $9.32(2.69)$ & -0.04 & & 0.19 & & -0.07 & \\
\hline Coding-digit symbol & $8.05(3.06)$ & -0.31 & & -0.12 & & -0.32 & \\
\hline
\end{tabular}

$p<0.001$ ), however the relationship between the impulsivity of HKD and ADHD domain was not significant $\left(R_{\mathrm{S}}=0.32 ; p=0.06\right)$. There was a highly significant correlation between inattention of HKD and inattention of $\operatorname{ADHD}\left(R_{\mathrm{S}}=0.98 ; p<0.001\right)$ (Table 1$)$.

The median values of the total IQ-98 (25th-75th percentile: 90-106), the Verbal IQ-102 (25th-75th percentile: 91-108) and the performance IQ-90 (25th-75th percentile: 87-106) were determined in all the study subjects. The Vocabulary subtest and the Comprehension subtest with the inattention domain showed a negatively significant correlation $\left(R_{\mathrm{S}}=-0.42 ; p=0.01\right.$ and $-0.49 ; p=0.002$, respectively) (Table 1 ).

The mean (SD) of MMP-9 levels 49.13 (15.86) $\mu \mathrm{g} / \mathrm{l}$ and median of MMP-9 levels $50.82 \mu \mathrm{g} / 1$ (25th percentile$43.14 \mu \mathrm{g} / \mathrm{l} ;$ 75th percentile-56.34 $\mu \mathrm{g} / \mathrm{l})$ in study group amounted. The General Regression Models (GRM) were used to assess the effect of MMP-9 on HKD/ADHD symptoms (Table 2). The MMP-9 levels were significantly associated with symptoms severity of HKD and of ADHD $(\beta=0.34 ; p=0.037$ and $\beta=0.33 ; p=0.043$, respectively) (Fig. 1a, b). Furthermore, serum MMP-9 concentrations correlated with increase impulsiveness $(\beta=0.38$; $p=0.019$ ) (Fig. 2a, b).

Analysis of the relationship between serum activity of MMP-9 and WISC-R subtests quotient measurements revealed no correlation. There was no relationship between age and the level of MMP-9 in the study group.

\section{Discussion}

To our best knowledge, this is the first study to assess the levels of MMP-9 in children with HKD/ADHD, and to investigate the correlation of MMP-9 with the cognitive function and symptoms severity. A certain limitation of our study was small group size. However, our intention was to include children with a very similar phenotype of HKD/ 
Table 2 MMP-9 levels in relation to cognitive domains of HKD/ ADHD

\begin{tabular}{lllllll}
\hline \multicolumn{1}{c}{$b$} & SE & $95 \%$ CI & & $\beta$ & $p$ \\
\hline HKD & & & & & & \\
MMP-9 & 0.043 & 0.02 & 0.003 & 0.084 & $\mathbf{0 . 3 4 *}$ & $\mathbf{0 . 0 3 7} *$ \\
$\begin{array}{c}\text { Inattention } \\
\text { MMP-9 }\end{array}$ & 0.021 & 0.012 & -0.003 & 0.045 & 0.29 & 0.085 \\
$\begin{array}{c}\text { Hyperactivity } \\
\text { MMP-9 }\end{array}$ & 0.004 & 0.012 & -0.021 & 0.028 & 0.05 & 0.770 \\
$\begin{array}{c}\text { Impulsivity } \\
\text { MMP-9 }\end{array}$ & 0.018 & 0.007 & 0.003 & 0.032 & $\mathbf{0 . 3 8 *}$ & $\mathbf{0 . 0 1 9} *$ \\
$\begin{array}{c}\text { ADHD } \\
\text { MMP-9 }\end{array}$ & 0.034 & 0.016 & 0.001 & 0.067 & $\mathbf{0 . 3 3 *}$ & $\mathbf{0 . 0 4 3} *$ \\
$\begin{array}{c}\text { Innatention } \\
\text { MMP-9 }\end{array}$ & 0.021 & 0.011 & -0.002 & 0.045 & 0.29 & 0.075 \\
$\begin{array}{c}\text { Hyperactivity/impulsivity } \\
\text { MMP-9 }\end{array}$ & 0.012 & 0.009 & -0.005 & 0.031 & 0.24 & 0.160 \\
\hline
\end{tabular}

$\beta$-standardized regression coefficient parameterization of sigma limits $b$ regression coefficient, $S E$ standard error, $C I$ confidence intervals

* Regression model statistically significant $p<0.05$

ADHD. In our study, the increased serum MMP-9 levels was correlated with the severity of symptoms in the HKD/ ADHD clinical model. Based on the data, elevated levels of serum MMP-9 in boys with HKD were specifically associated with clinical impulsivity domain.

The motivation and reward, may represent another core deficit for ADHD [53]. Children with ADHD/HKD are incapable of to the self-control, reveal rapid unplanned reactions and difficulty of postponing award [54, 55]. Experimental models of the impulsivity emphasize repeatability even though behaviours are punishable [56]. The concept of impulsivity domain for HKD in accordance with the ICD-10 includes four symptoms, whereas the impulsivity is not a separate domain for ADHD in DSM IV or DSM V [34-37, 57]. One of the four impulsivity symptoms for HKD: "Talks excessively" is categorized as a symptom of hyperactivity in DSM-IV and DSM-V [36, 37]. This had important implications for the interpretation of our findings. Unclear conceptualization of the impulsivity domain may have influenced the differences in the correlation between serum MMP-9 levels and HKD-model or ADHD-model in the study group.

Our research shows that the severity of symptoms affects WISC-R results. We found a significant negative correlation between severity of inattention and the Vocabulary and Comprehension subtests, which form Verbal Conceptual Thinking (can shape account for social intelligence, verbalization, memory recall) $[33,58]$. It has been proved that the attention deficit is most disturbing factor in the social functioning of children with ADHD/

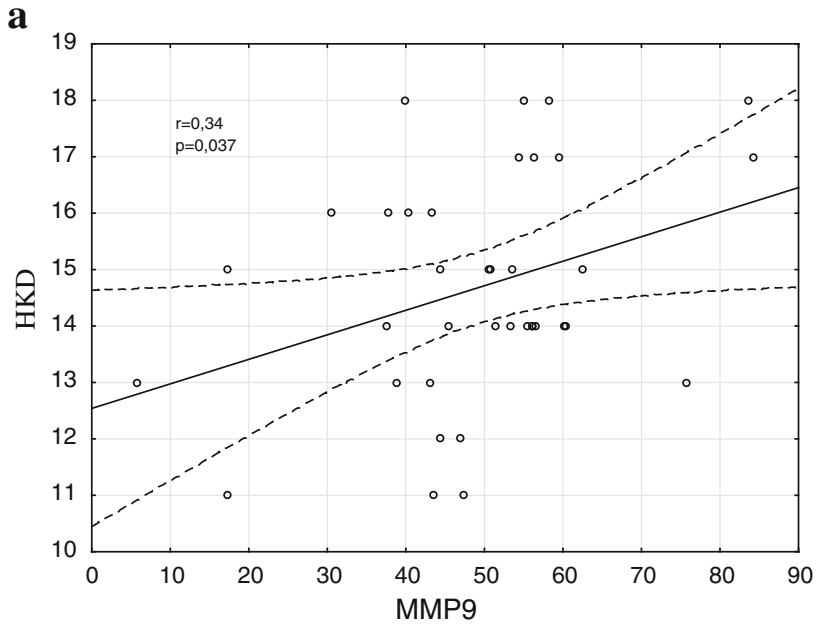

b

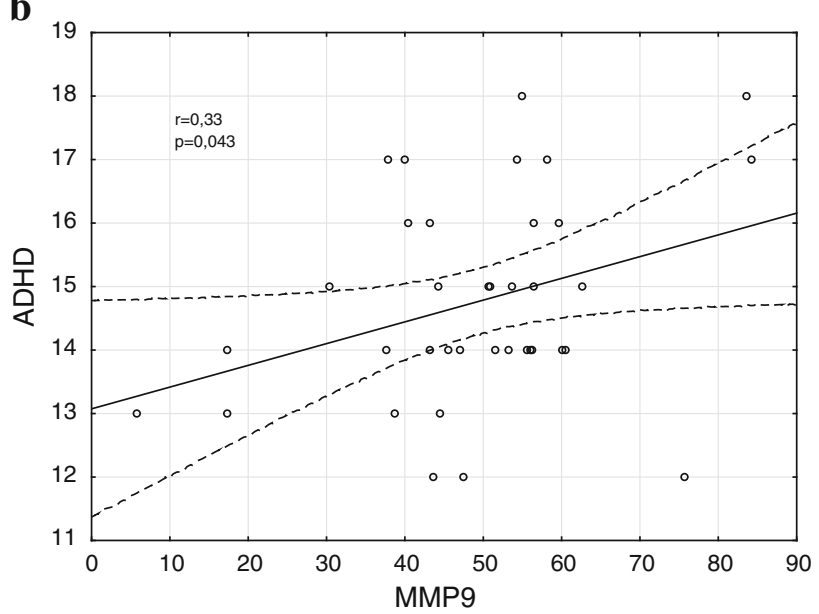

Fig. 1 The symptom severity and MMP-9 levels in boys with HKD/ ADHD

HKD. Symptoms of inattention hinder to establish social relationships through observation and focus on the social factors, that are essential for supporting interaction [30, 31, 59]. Most authors agree that children with a diagnosis of combined ADHD subtype present with difficulties in the largest number of areas of cognitive and psychosocial functioning [32, 40, 41, 44, 47], but the reasons for the existence of cognitive deficits in children with ADHD/ HKD are still unclear. Recent PET brain imaging studies revealed, that the most DA deficits were evident in the ventral striatum (modulation of reward and motivation) and in the midbrain (where most DA neurons are located) [60], which supports the DA hypothesis of ADHD [61, 62], although the specific details are not yet clear. Dopamine transporter DAT, which is located in dendrites and axonal membrane, or activation of dopamine receptors may be responsible for dopamine levels [62, 63]. Although most studies have been focused on the prefronto-striatal system [64], others, concerned with psychopharmacology and 


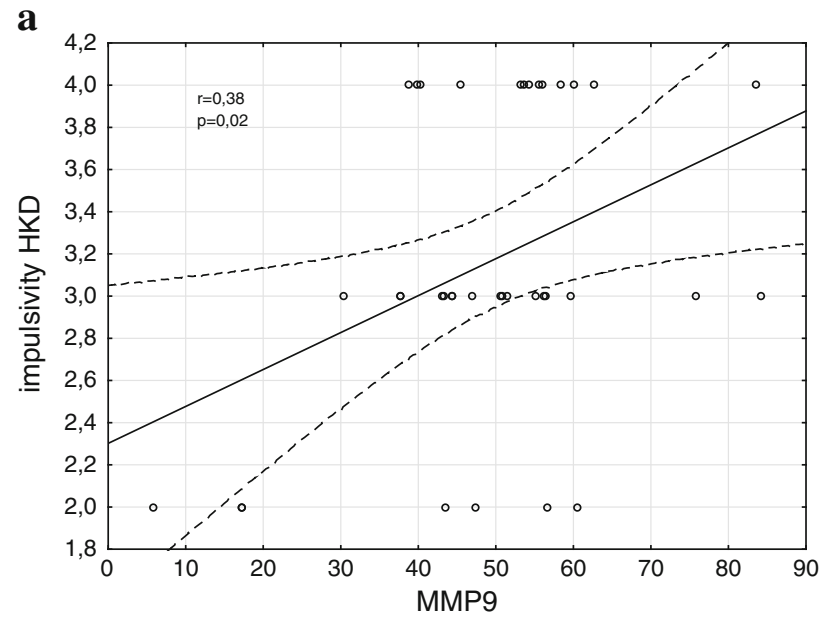

b

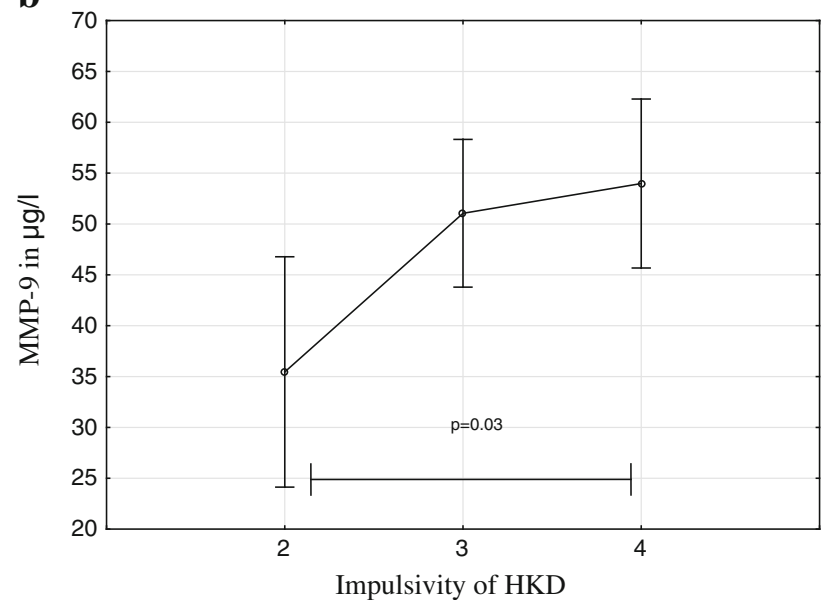

Fig. 2 MMP-9 levels and Impulsivity

neuroimaging (MRI, fMRI) of brain processes, have pointed to many cortical and subcortical brain regions implicated in ADHD [65-67]. Furthermore, it has been recently shown that many neural networks are involved in cognitive and behavioural symptoms of ADHD [68-71]. Researchers who have defined the pattern for typical brain development suggest that some childhood onset cases may be disorders of neuroplasticity [72-74]. Some studies support this hypothesis for autism or schizophrenia [73, 75]. The plasticity is a property of the nervous system that provides the capability for adaptation, self-healing, learning and memory [73].

The extracellular proteolysis by MMP-9 is important for the functional and structural synaptic plasticity $[1,2,5-7,9$, 10]. Matrix metalloproteinase- 9 is expressed in the hippocampus, striatum, diencephalon, midbrain, cerebellum and frontal cortex of the rat $[3,6,76,78]$, with the greatest activity in the hippocampus $[14,15,24,77]$. The contribution of MMP-9 in addictions to methamphetamine [79, 80] or cocaine [76] may suggest its role in dopamine neurotransmission. This enzyme, located in dendritic spines is responsible for the structural changes in synapses and thereby may be partly responsible for the improper regulation of extracellular dopamine levels [81]. Matrix metalloproteinase- 9 is required for the formation of abnormal synaptic connections between hippocampal granule cell axons and their dendrites in rodent brain, and is also related to immature dendritic spine morphology [82]. The level of this enzyme is elevated in Fragile X syndrome (FXS), in which inattention, impulsivity and hyperactivity are manifested beside autism, and administration of minocycline (MMP-9 inhibitor) to mouse model of FXS results in normalization of behaviours and a decrease in anxiety [83]. Despite the absence of clinical symptoms of ASD in our study boys, according to research, inadequate social behaviours in children with ADHD may be phenomenologically and etiologically related to autism spectrum disorders $[84,85]$.

The MMP-9 concentration increases in inflammation, hypoxia or injuries of brain, where the blood-brain barrier is damaged [11-17, 86]. This leads to the hypothesis that prenatal environmental risk factors for ADHD, such as viral infections, asphyxia, neurotoxins, alcohol or nicotine can affect the expression of MMP-9, and consequently the long-term alteration in blood-brain barrier permeability to small-molecular-weight markers [12, 75]. Minocycline through inhibition of MMP-9, reduces permeability of sucrose during intracerebral injection [86]. Another hypothesis is related to continuous disturbances in MMP-9 gene transcription by unknown specific factors, which may be supported by the result of mutation in FMR1gene (leading to autism), in which the FMpR protein, natural of MMP-9 translation inhibitor, is missing. In the animal model (Fmfr1KO mice), administration of minocycline resulted in maturation hippocampal dendritic spines and behaviour improvement [83].

Though the relevant scientific studies gained great interest in recent decades, the etiopathogenesis and underlying mechanism of ADHD/HKD remain still unclear. So far, laboratory, psychological or biological studies that could be specific enough to allow explicit in diagnosis of ADHD/HKD have been missing [36]. The structuralised interview and either ICD-10 or DSM-IV/DSM-V are the fundamental elements of diagnosis. However, some variation in the domain of impulsivity may suggest difficulty in understanding the place for cognitive deficits in the clinical diagnosis of ADHD/ HKD. Therefore, a genetic defect determines a certain predisposition to ADHD/HKD but environmental factors contribute largely to the phenotype of the disorder $[72,87]$. The mechanism of the impact of unexplained environmental factors is not clear, but MMP-9 may be associated with the severity of symptoms.

To understand the processes engaged in cognitive dysfunction in $\mathrm{ADHD} / \mathrm{HKD}$, it is necessary to unravel 
signalling pathways, complex interaction networks and metabolic alterations involving many anatomical components. However, we are aware that the role of MMP-9 in neurodevelopmental damage still remains unclear, and the present study is the first to show the elevated levels of serum MMP-9 in boys with HKD correlated with severity of the disorder. The results indicate that the increased levels of serum MMP-9 in boys with HKD are associated with the clinical domain of impulsivity.

Acknowledgments This study was supported by a Grant 3-26601L from the Medical University of Bialystok. We are grateful to biostatisticians: Dr Jerzy Sienkiewicz from the Centre for Science and Research of Podlaskie and Dr Robert Milewski from Department of Statistics and Medical Informatics of Medical University of Bialystok for help in the statistical analysis. We would also like to thank Jason Crase Editorial Specialist of the Division of Publishing and Production Services in the American Academy of Pediatrics (AAP) and Pat Heinrich Chief Quality Improvement Director of The National Initiative for Children's Healthcare Quality (NICHQ) for the availability of NICHQ Vanderbilt Assessment Scales.

\section{Conflict of interest None.}

Open Access This article is distributed under the terms of the Creative Commons Attribution License which permits any use, distribution, and reproduction in any medium, provided the original author(s) and the source are credited.

\section{References}

1. Ethell IM, Ethell DW (2007) Matrix metalloproteinases in brain development and remodeling: synaptic functions and targets. J Neurosci Res 85(13):2813-2823

2. Fujioka H, Dairyo Y, Yasunaga K, Emoto K (2012) Neural functions of matrix metalloproteinases: plasticity, neurogenesis, and disease. Biochem Res Int 2012:789083. doi:10.1155/2012/789083

3. Kaneko M, Yamaguchi K, Eiraku M, Sato M, Takata N, Kiyohara Y, Mishina M, Hirase H, Hashikawa T, Kengaku M (2011) Remodeling of monoplanar purkinje cell dendrites during cerebellar circuit formation. PLoS One 6(5):e20108

4. Li Q, Liu J, Michaud M, Schwartz ML, Madri JA (2009) Strain differences in behavioral and cellular responses to perinatal hypoxia and relationships to neural stem cell survival and selfrenewal: modeling the neurovascular niche. Am J Pathol 175(5):2133-2146

5. Verslegers M, Lemmens K, Van Hove I, Moons L (2013) Matrix metalloproteinase-2 and -9 as promising benefactors in development, plasticity and repair of the nervous system. Prog Neurobiol 105:60-78

6. Yong VW, Power C, Forsyth P, Edwards DR (2001) Metalloproteinases in biology and pathology of the nervous system. Nat Rev Neurosci 2(7):502-511

7. Dityatev A, Schachner M, Sonderegger P (2010) The dual role of the extracellular matrix in synaptic plasticity and homeostasis. Nat Rev Neurosci 11:735-746

8. Zimmermann DR, Dours-Zimmermann MT (2008) Extracellular matrix of the central nervous system: from neglect to challenge. Histochem Cell Biol 130(4):635-653

9. Fellin T (2009) Communication between neurons and astrocytes: relevance to the modulation of synaptic and network activity. J Neurochem 108(3):533-544
10. Yamada S, Nelson WJ (2007) Synapses: sites of cel recognition, adhesion and functional specification. Ann Rev Biochem 76:267-794

11. Candelario-Jalil E, Thompson J, Taheri S, Grossetete M, Adair JC, Edmonds E, Prestopnik J, Wills J, Rosenberg GA (2011) Matrix metalloproteinases are associated with increased bloodbrain barrier opening in vascular cognitive impairment. Stroke 42(5):1345-1350

12. Duran-Vilaregut J, del Valle J, Manich G, Camins A, Pallàs M, Vilaplana J, Pelegrí C (2011) Role of matrix metalloproteinase-9 (MMP-9) in striatal blood-brain barrier disruption in a 3-nitropropionic acid model of Huntington's disease. Neuropathol Appl Neurobiol 37(5):525-537

13. Leonardo CC, Hall AA, Collier LA, Gottschall PE, Pennypacker KR (2009) Inhibition of gelatinase activity reduces neural injury in an ex vivo model of hypoxia-ischemia. Neuroscience 160(4):755-766

14. Lu L, Tonchev AB, Kaplamadzhiev DB, Boneva NB, Mori Y, Sahara S, Ma D, Nakaya MA, Kikuchi M, Yamashima T (2008) Expression of matrix metalloproteinases in the neurogenic niche of the adult monkey hippocampus after ischemia. Hippocampus 18(10):1074-1084

15. Martins T, Baptista S, Gonçalves J, Leal E, Milhazes N, Borges F, Ribeiro CF, Quintela O, Lendoiro E, López-Rivadulla M, Ambrósio AF, Silva AP et al (2011) Methamphetamine transiently increases the blood-brain barrier permeability in the hippocampus: role of tight junction proteins and matrix metalloproteinase-9. Brain Res 1411:28-40

16. Ainiala H, Hietaharju A, Dastidar P, Loukkola J, Lehtimäki T, Peltola J, Korpela M, Heinonen T, Nikkari ST (2004) Increased serum matrix metalloproteinase 9 levels in systemic lupus erythematosus patients with neuropsychiatric manifestations and brain magnetic resonance imaging abnormalities. Arthritis Rheum 50(3):858-865

17. Gaudet JG, Yocum GT, Lee SS, Granat A, Mikami M, Connolly ES Jr, Heyer EJ (2010) MMP-9 levels in elderly patients with cognitive dysfunction after carotid surgery. J Clin Neurosci 17(4):436-440

18. Lim NK, Villemagne VL, Soon CP, Laughton KM, Rowe CC, McLean CA, Masters CL, Evin G, Li QX (2011) Investigation of matrix metalloproteinases, MMP-2 and MMP-9, in plasma reveals a decrease of MMP-2 in Alzheimer's disease. J Alzheimers Dis 26(4):779-786

19. Lorenzl S, Buerger K, Hampel H, Beal MF (2008) Profiles of matrix metalloproteinases and their inhibitors in plasma of patients with dementia. Int Psychogeriatr 20(1):67-76

20. Rybakowski JK, Remlinger-Molenda A, Czech-Kucharska A, Wojcicka M, Michalak M, Losy J (2013) Increased serum matrix metalloproteinase-9 (MMP-9) levels in young patients during bipolar depression. J Affect Disord 146(2):286-289. doi:10.1016/ j.jad.2012.07.019

21. Konopka A, Grajkowska W, Ziemiańska K, Roszkowski M, Daszkiewicz P, Rysz A, Marchel A, Koperski L, Wilczyński GM, Dzwonek J (2013) Matrix metalloproteinase-9 (MMP-9) in human intractable epilepsy caused by focal cortical dysplasia. Epilepsy Res. 104(1-2):45-58. doi:10.1016/j.eplepsyres.2012.09. 018

22. Bruno MA, Mufson EJ, Wuu J, Cuello AC (2009) Increased matrix metalloproteinase 9 activity in mild cognitive impairment. J Neuropathol Exp Neurol 68(12):1309-1318

23. Martín-Aragón S, Bermejo-Bescós P, Benedí J, Felici E, Gil P, Ribera JM, Villar AM (2009) Metalloproteinase's activity and oxidative stress in mild cognitive impairment and Alzheimer's disease. Neurochem Res 34(2):373-378

24. Bozdagi O, Nagy V, Kwei KT, Huntley GW (2007) In vivo roles for matrix metalloproteinase-9 in mature hippocampal synaptic physiology and plasticity. J Neurophysiol 98(1):334-344 
25. Helbecque N, Hermant X, Cottel D, Amouyel P (2003) The role of matrix metalloproteinase-9 in dementia. Neurosci Lett 350(3):181-183

26. Barkley RA (1997) Behavorial inhibition, sustained attention, and executive functions: constructing a unifying theory of ADHD. Psychol Bull 121:65-94

27. Bowers TG, Risser MG, Suchanec JF, Tinker DE, Ramer JC, Domoto M (1992) A developmental index using the Wechsler Intelligence Scale for Children: implications for the diagnosis and nature of ADHD. J Learn Disabil 25(3):179-185

28. Drechsler R, Brandeis D, Foldenyi M, Imhof K, Steinhausen HC (2005) The course of neuropsychological functions in children with attention deficit hyperactivity disorder from late childhood to early adolescence. J Child Psychol Psychiatry 46:824-836

29. Halperin JM, Trampush JW, Miller CJ, Marks DJ, Newcorn JH (2008) Neuropsychological outcome in adolescents/young adults with childhood ADHD: profiles of persisters, remitters and controls. J Child Psychol Psychiatry 49:958-966

30. Mrug S, Hoza B, Pelham WE, Gnagy EM, Greiner AR (2007) Behavior and peer status in children with ADHD: continuity and change. J Atten Disord 10:359-371

31. Nigg JT, Willcutt EG, Doyle AE, Sonuga-Barke EJ (2005) Causal heterogeneity in attention-deficit/hyperactivity disorder: do we need neuropsychologically impaired subtypes? Biol Psychiatry 57:1224-1230

32. Pineda D, Ardila A, Rosselli M (1999) Neuropsychological and behavioral assessment of ADHD in seven- to twelve-year-old children: a discriminant analysis. J Learn Disabil 32(2):159-173

33. Willcutt EG, Doyle AE, Nigg JT, Faraone SV, Pennington BF (2005) Validity of the executive function theory of attentiondeficit/hyperactivity disorder: a meta-analytic review. Biol Psychiatry 57(11):1336-1346

34. Swanson J, Baler RD, Volkow ND (2011) Understanding the effects of stimulant medications on cognition in individuals with attention-deficit hyperactivity disorder: a decade of progress. Neuropsychopharmacology 36(1):207-226. doi:10.1038/npp. 2010.160

35. APA (2000) Diagnostics and statistical manual of mental disorders, text revision DSM-IV-TR, 4th edn. American Psychiatric Association, Washington DC

36. APA (2013) Diagnostics and statistical manual of mental disorders, DSM-V, 5th edn. American Psychiatric Association, Washington DC, London

37. WHO (1992) The ICD-10 classification of mental and behavioral disorders: clinical descriptions and diagnostic guidelines. World Health Organization, Geneva

38. Muir-Broaddus JE, Rosenstein LD, Medina DE, Soderberg C (2002) Neuropsychological test performance of children with ADHD relative to test norms and parent behavioral ratings. Arch Clin Neuropsychol 17(7):671-689

39. Kelly A, Uddin L, Biswal B, Castellanos F, Milham M (2008) Competition between functional brain networks mediates behavioral variability. Neuroimage 39(1):527-537

40. Naglieri JA, Goldstein S, Delauder BY, Scwebach A (2005) Relationships between the WISC-III and the cognitive assessment system with Conners? Rating scales and continuous performance tests. Arch Clin Neuropsychol 20:385-401

41. Chhabildas N, Pennington BF, Willcutt EG (2001) A comparison of the neuropsychological profiles of the DSM-IV subtypes of ADHD. J Abnorm Child Psychol 29(6):529-540

42. Evinç SG, Gençöz T (2007) WISC-R profiles of children with attention deficit hyperactivity disorder: a comparative study. Turk Psikiyatri Derg 18(2):109-117

43. Mayes SD, Calhoun SL (2006) WISC-IV and WISC-III profiles in children with ADHD. J Atten Disord 9(3):486-493
44. Geurts HM, Vertr S, Oosterlaan J, Roeyers H, Sergeant JA (2005) ADHD subtypes: do they differ in their executive functioning profile? Arch Clin Neuropsychol 20(4):457-477

45. Nigg JT (2005) Neuropsychologic theory and findings in attention-deficit/hyperactivity disorder: the state of the field and salient challenges for the coming decade. Biol Psychiatry 57(11):1424-1435

46. Mayes SD, Calhoun SL (2002) The Gordon Diagnostic System and WISC-III freedom from Distractibility Index: validity in identifying clinic-referred children with and without ADHD. Psychol Rep 91(2):575-587

47. Tripp G, Ryann J, Peace K (2002) Neuropsychological functioning in children with DSM-IV combined type attention deficit hyperactivity disorder. Aust N Z J Psychiatry 36:771-779

48. Kaplan BJ, Crawford SG, Dewey DM (2000) The IQ of children with ADHD are normally distributed. J Learn Disabil 33(5):425-432

49. NICHQ, AAP (2002) Vanderbilt assessment scales (parentinformant, teacher-informant). In: Caring for children With ADHD: a resource toolkit for clinicians

50. Bard DE, Wolraich ML, Neas B, Doffing M, Beck L (2013) The psychometric properties of the Vanderbilt attention-deficit hyperactivity disorder diagnostic parent rating scale in a community population. J Dev Behav Pediatr 34(2):72-82

51. Wolraich ML, Bard DE, Neas B, Doffing M, Beck L (2013) The psychometric properties of the Vanderbilt attention-deficit hyperactivity disorder diagnostic teacher rating scale in a community population. J Dev Behav Pediatr 34(2):83-93

52. Wechsler D (1974) WISC-R manual for the Wechsler Intelligence Scale for children-revised. Psychological Corporation, New York

53. Shanahan MA, Pennington BF, Willcutt EW (2008) Do motivational incentives reduce the inhibition deficit in ADHD. Dev Neuropsychol 33:137-159

54. Kenemans JL, Bekker EM, Lijffijt M, Overtoom CC, Jonkman LM, Verbaten MN (2005) Attention deficit and impulsivity: selecting, shifting, and stopping. Int J Psychophysiol 58:59-70

55. Luman M, Oosterlaan J, Knol DL, Sergeant JA (2008) Decisionmaking in ADHD: sensitive to frequency but blind to the magnitude of penalty? J Child Psychol Psychiatry 49(7):712-722

56. Monterosso J, Ainslie G (1999) Beyond discounting: possible experimental models of impulse control. Psychopharmacology 146(4):339-347

57. Swanson JM, Sergeant JA, Taylor E, Sonuga-Barke EJ, Jensen PS, Cantwell DP (1998) Attention-deficit hyperactivity disorder and hyperkinetic disorder. Lancet 351:429-433

58. Bannatyne A (1974) Diagnosis: a note recategorization of the WISC scaled scores. J Learn Disabil 7:272-274

59. Hoza B (2007) Peer functioning in children with ADHD. J Pediatr Psychol 32(6):655-663

60. Volkow ND, Fowler JS, Logan J, Alexoff D, Zhu W, Telang F, Wang GJ, Jayne M, Hooker JM, Wong C, Hubbard B, Carter P, Warner D, King P, Shea C, Xu Y, Muench L, Apelskog-Torres K (2009) Effects of modafinil on dopamine and dopamine transporters in the male human brain: clinical implications. JAMA 301:1148-1154

61. Volkow ND, Wang GJ, Newcorn J, Fowler JS, Telang F, Solanto MV, Logan J, Wong C, Ma Y, Swanson JM, Schulz K, Pradhan K (2007) Brain dopamine transporter levels in treatment and drug naïve adults with ADHD. Neuroimage 34:1182-1190

62. Tripp G, Wickens JR (2008) Research review: dopamine transfer deficit: a neurobiological theory of altered reinforcement mechanisms in ADHD. J Child Psychol Psychiatry 49:691-704

63. Krause J (2008) SPECT and PET of the dopamine transporter in attention-deficit/hyperactivity disorder. Expert Rev Neurother $8: 611-625$ 
64. Carmona S, Proal E, Hoekzema EA, Gispert JD, Picado M, Moreno I, Soliva JC, Bielsa A, Rovira M, Hilferty J, Bulbena A, Casas M, Tobeña A, Vilarroya O (2009) Ventro-striatal reductions underpin symptoms of hyperactivity and impulsivity in attention-deficit/hyperactivity disorder. Biol Psychiatry 66:972-977

65. Fox M, Raichle M (2007) Spontaneous fluctuations in brain activity observed with functional magnetic resonance imaging. Nat Rev Neurosci 8:700-711

66. Krain A, Castellanos F (2006) Brain development and ADHD. Clin Psychol Rev 26:433-444

67. Paloyelis Y, Mehta MA, Kuntsi J, Asherson P (2007) Functional MRI in ADHD: a systematic literature review. Expert Rev Neurother 7:1337-1356

68. Bush G (2010) Attention-deficit/hyperactivity disorder and attention networks. Neuropsychopharmacology 35(1):278-300

69. Dosenbach NU, Fair DA, Miezin FM, Cohen AL, Wenger KK, Dosenbach RA, Fox MD, Snyder AZ, Vincent JL, Raichle ME, Schlaggar BL, Petersen SE (2007) Distinct brain networks for adaptive and stable task control in humans. Proc Natl Acad Sci USA 104:11073-11078

70. Fassbender C, Schweitzer J (2006) Is there evidence for neural compensation in attention deficit hyperactivity disorder? A review of the functional neuroimaging literature. Clin Psychol Rev 26:445-465

71. Konrad K, Neufang S, Hanisch C, Fink GR, Herpertz-Dahlmann B (2006) Dysfunctional attentional networks in children with attention deficit/hyperactivity disorder: evidence from an eventrelated functional magnetic resonance imaging study. Biol Psychiatry 59:643-651

72. Lenroot RK, Gledd JN (2008) The changing impact of genes and environment on brain development during childhood and adolescence: initial findings from a neuroimaging study of pediatric twins. Dev Psychopathol 20:1161-1175

73. Rapoport JL, Gogtay N (2008) Brain neuroplasticity in healthy, hyperactive and psychotic children: insights from neuroimaging. Neuropsychopharmacology 33:181-197

74. Shaw P, Gogtay N, Rapoport J (2010) Childhood psychiatric disorders as anomalies in neurodevelopmental trajectories. Hum Brain Mapp 31:917-925

75. Stolp HB, Dziegielewska KM, Ek CJ, Potter AM, Saunders NR (2005) Long-term changes in blood-brain barrier permeability and white matter following prolonged systemic inflammation in early development in the rat. Eur J Neurosci 22:2805-2816

76. Brown TE, Forquer MR, Harding JW, Wright JW, Sorg BA (2008) Increase in matrix metalloproteinase-9 levels in the rat medial prefrontal cortex after cocaine reinstatement of conditioned place preference. Synapse 62(12):886-889
77. Szklarczyk A, Lapinska J, Rylski M, McKay RD, Kaczmarek L (2002) Matrix metalloproteinase-9 undergoes expression and activation during dendritic remodeling in adult hippocampus. J Neurosci 22(3):920-930

78. Zhang JW, Deb S, Gottschall PE (1998) Regional and differential expression of gelatinases in rat brain after systemic kainic acid or bicuculline administration. Eur J Neurosci 10(11):3358-3368

79. Mizoguchi H, Yamada K, Mouri A (2007) Role of matrix metalloproteinase and tissue inhibitor of MMP in methamphetamine-induced behavioral sensitization and reward: implications for dopamine receptor down-regulation and dopamine release. J Neurochem 102(5):1548-1560

80. Mizoguchi H, Yamada K, Nabeshima T (2008) Neuropsychotoxicity of abused drugs: involvement of matrix metalloproteinase- 2 and -9 and tissue inhibitor of matrix metalloproteinase- 2 in methamphetamine-induced behavioral sensitization and reward in rodents. J Pharmacol Sci 106(1):9-14

81. Nagai T, Yamada K, Yoshimura M, Ishikawa K, Miyamoto $Y$, Hashimoto K, Noda Y, Nitta A, Nabeshima T (2004) The tissue plasminogen activator-plasmin system participates in the rewarding effect of morphine by regulating dopamine release. Proc Natl Acad Sci 101(10):3650-3655

82. Wang XB, Bozdagi O, Nikitczuk JS, Zhai ZW, Zhou Q, Huntley GW (2008) Extracellular proteolysis by matrix metalloproteinase-9 drives dendritic spine enlargement and long-term potentiation coordinately. Proc Natl Acad Sci USA 105(49):19520-19525. doi:10.1073/pnas.0807248105

83. Wang LW, Berry-Kravis E, Hagerman RJ (2010) Fragile X: leading the way for targeted treatments in autism. Neurotherapeutics 7(3):264-274

84. van der Meer JM, Oerlemans AM, van Steijn DJ, Lappenschaar MG, de Sonneville LM, Buitelaar JK, Rommelse NN (2012) Are autism spectrum disorder and attention-deficit/hyperactivity disorder different manifestations of one overarching disorder? Cognitive and symptom evidence from a clinical and population-based sample. J Am Acad Child Adolesc Psychiatry 51(11):1160-1172

85. Sikora DM, Vora P, Coury DL, Rosenberg D (2012) Attentiondeficit/hyperactivity disorder symptoms, adaptive functioning, and quality of life in children with autism spectrum disorder. Pediatrics 130(Suppl 2):S91-S97

86. Rosenberg GA, Estrada EY, Mobashery S (2007) Effect of synthetic matrix metalloproteinase inhibitors on lipopolysaccharideinduced blood-brain barrier opening in rodents: differences in response based on strains and solvents. Brain Res 1133:186-192

87. Larsson J, Larsson H, Lichtenstein P (2004) Genetic and environmental contributions to stability and change of ADHD symptoms between 8 and 13 years of age: a longitudinal twin study. J Am Acad Child Adolesc Psychiatry 43(10):1267-1275 